\title{
Continuidades da narrativa Freyriana na construção de imagens das mulheres brasileiras
}

\author{
Layla Pedreira de Carvalho*
}

\begin{abstract}
Resumo: O objetivo deste trabalho é analisar as contribuições de Gilberto Freyre na construção de identidades femininas no Brasil, a partir da elaboração de imagens das mulheres brasileiras desde o período colonial. Delineamos o tratamento de Freyre às mulheres negras, indígenas e brancas, sendo a análise feita à luz da proposta da epistemologia feminista, da manutenção de um olhar crítico sobre a produção científica. Buscamos então evidenciar a presença marcante das construções de Freyre nos trabalhos de releitura da história brasileira que têm como objetivo evidenciar a presença feminina e retirar o silêncio histórico da existência delas, mas que fazem uma inserção problemática devido a esse apego às construções de Freyre.
\end{abstract}

Palavras-chave: Gilberto Freyre; história das mulheres; imagens de mulheres.

Abstract: The object of this work is to analyze the contributions of Gilberto Freyre in the construction of feminine identity in Brazil, through the elaboration of images of Brazilian women since the colonial period. We delineate the treatment by Freyre to negress, indigenous and white women and the analysis is carried out in the light of a feminist epistemology proposal through the maintenance of a critical eye about scientific production. We therefore sought to show the outstanding presence of Freyre's constructions in the re-reading work of Brazilian history, the objective of which is to show the feminine presence and remove the historic silence about them, which however makes a problematic insertion due to this attachment to Freyre constructions.

Keywords: Gilberto Freyre; history of women; image of women.

Acreditando na produção científica como um espaço que guarda enormes possibilidades de construção de novas leituras da realidade e do questionamento de ordens estabelecidas, assim como defendem inúmeras teóricas da história das mulheres, é que nasce este trabalho. Nosso objetivo é analisar as contribuições de Gilberto Freyre na construção de identidades femininas no Brasil, a partir da elaboração de características das mulheres brasileiras desde o período colonial.

As contribuições de Freyre são ainda muito importantes como referências de identidade da sociedade brasileira, mais por seu amplo uso e difusão que por uma correção das impressões que esse "menino de engenho" do Recife elaborou sobre relações de dominação na formação da família patriarcal brasileira; sejam elas étnicas/raciais, sexuais ou

\footnotetext{
"Mestranda em Sociologia na Universidade de Brasília, layla@unb.br 
sociais. Pela ampla repetição de estereótipos que ganharam notoriedade por meio das páginas de Freyre, como a figura da mulata sensual, ou da mulher subserviente e bondosa, aproximada à figura da Virgem Maria, temos dificuldades em romper com esse conhecimento localizado e, na perspectiva das mulheres, misógino e imobilista.

Tomaremos como base da análise os livros Casa Grande \& Senzala e Sobrados \& Mucambos. Marcaremos o tratamento de Freyre às mulheres negras, indígenas e brancas no Brasil Colônia e no Império, períodos abarcados pelas obras escolhidas. A importância fundamental dessa observação reside na tentativa de seguir a proposta das teóricas feministas da manutenção de um olhar crítico sobre a produção científica. Nessa perspectiva sugerimos o uso cuidadoso e crítico das contribuições de Gilberto Freyre por estudiosas(os) que pretendam tratar da inserção das mulheres brasileiras na historiografia nacional, tendo em vista o caráter sexista daquilo que pretende ser uma descrição fiel do cotidiano das mulheres nas casasgrandes, nos sobrados, nas senzalas e nos mucambos.

O trabalho tem três pontos centrais: num primeiro momento delinearemos nossa preocupação com a necessidade de uma epistemologia feminista, com a crítica das pesquisas que, impelidas a ignorar a presença das mulheres por uma narrativa que privilegia os homens, produzem relatos ou que as exclui ou que trazem de forma deformada sua participação na história, assim como vemos em Freyre.

Num segundo momento, trataremos especificamente do trabalho de Freyre tomando as bases da naturalização de papéis de homens e mulheres e a centralidade do erotismo e da prática sadomasoquista no Brasil, que segundo Freyre, caracterizam o patriarcalismo brasileiro em todas as relações entre dominadores e dominados, vinculados a uma permissividade do sistema econômico formador da nação brasileira. Em todos esses momentos o tratamento de Freyre dado a mulheres brancas, negras e indígenas será o foco do trabalho, marcando então os traços da misoginia e sexismo que atribuímos às páginas de Freyre.

Como último ponto, traremos as heranças da narrativa agressiva de Freyre nos trabalhos de historiadoras das mulheres no Brasil, de obras a partir dos anos 1980, defendendo a que parece difícil, mas necessária, quebra com argumentos tão aceitos como os de Freyre. Aqui observaremos a marca da misoginia freyriana nas páginas de trabalhos com objetivos interessantes, como o de Sonia Maria Giacomini, mas que se perdem ao tomarem as contribuições de Freyre como positivas para a elaboração de um relato sobre a história das mulheres no Brasil. 


\section{A importância de uma epistemologia feminista}

"A riqueza da epistemologia feminista está em sua incessante autocrítica, excedendo seus próprios pressupostos a fim de criar, na linguagem e na experiência, saídas para um pensamento agrilhoado a seus pressupostos."

(SWAIN, 2004, p. 48)

O questionamento feminista e a inserção das mulheres no debate científico criam a necessidade do desenvolvimento de uma nova epistemologia porque produzem uma nova maneira de pensar a realidade, exigindo mais que "um acréscimo das mulheres aos estudos, uma descoberta de suas histórias e de suas vozes. Essas problematizações desafiaram a própria forma de fazer ciência até então hegemônica"(LOURO, 144), sendo insuficiente que as mulheres apareçam nos estudos científicos, fazendo-se necessária a reconstrução da perspectiva científica até então tomada como possível e verdadeira.

O desafio lançado pelas teóricas feministas é a construção de narrativas que englobem as mulheres em suas especificidades, como sujeitos da história, agindo dentro das condições de vida possíveis para o tempo em que vivem, mais do que rebeldes ou vítimas do processo histórico, como lembra Soihet, como participantes ativas do momento social em que estão. Mais do que a criação de uma identidade fixa, como é proposto em muitos momentos por Freyre, dentro do interesse do nosso trabalho, o que as teóricas feministas de estudos das mulheres propõem é o reconhecimento do caráter transitório das identidades e dos interesses, tudo fazendo parte de um processo em constante formação e mudança. Assim, "constatou-se que 'a mulher' não existe; existem mulheres e como indivíduos ou grupos têm uma trajetória singular" (SWAIN, 2004, p. 45), a proposta não é a inclusão da vida das mulheres como instituições, mas como processos históricos, vinculados ao período em que se desenvolvem, tendo como finalidade última transcender qualquer definição do feminino, qualquer vinculação biológica ou social que essencialize a divisão binária: homem/mulher ou masculino/feminino.

$\mathrm{Na}$ narrativa freyriana que nos propomos estudar não são 'mulheres' que estão presentes: a construção elaborada pelo autor remete-se a modelos fixos de mulher e de homem, caracterizados, biologicamente, pelo sexo. Apesar da análise que toma as contribuições de mulheres brancas, negras e indígenas na formação da família patriarcal no Brasil, o que consideraria a multiplicidade das posições ocupadas por elas durante o período colonial e imperial, há diversos momentos da narrativa em que o importante, como 
problematizaremos mais adiante, são as determinações do sexo biológico de mulheres e homens, superando qualquer tipo de organização social.

Voltando às perspectivas lançadas pelos estudos das mulheres na academia, e tomando como referência o debate científico sobre a objetividade, a afirmação mais comum das teóricas feministas é que ela seria uma forma de institucionalizar a exclusão de certos assuntos e de manter no limbo as minorias ${ }^{1}$, como as mulheres. O que defendem as teóricas feministas é que a objetividade tão propalada como base de diferenciação das ciências de outros pontos de vista é apenas uma parcialidade, um ponto de vista construído a partir de experiências e de escolhas do cientista. A proposta apresentada por Haraway, que não desconsidera a importância da objetividade na elaboração das ciências, é a de uma objetividade conseguida por meio de um posicionamento da realidade, "a objetividade feminista significa, simplesmente, saberes localizados" (HARAWAY, 1995, p. 18).

É dentro dessa concepção do saber necessariamente interessado e da proposição de uma objetividade que passa pela localização, que a ciência feminista coloca como objetivos não ser imortal nem ser onipotente (Haraway, 1995). Ou seja, não existe a pretensão de explicar tudo definitivamente, mas tampouco se aceita a concepção de que outra abordagem da realidade seja capaz de fazê-lo. É então bastante claro o impacto dos estudos feministas na consideração das ciências: a assunção da parcialidade e da transitoriedade dos conhecimentos produzidos.

Dessa forma, a proposta de saberes localizados, feita por Donna Haraway, e do 'excesso', feita por Tânia Swain, podem ser resumidas como a busca pela aceitação do que Maria Odila Dias chama de incertezas colocadas ao conhecimento cartesiano. Da aceitação do caráter relativo do conhecimento. Relativo, não porque abarque tudo sem cuidar de nada como acusa Haraway, mas porque se coloca vinculado a determinado momento histórico e se desenvolve num processo de historicização, trazendo à tona o caráter instável do conhecimento e da sua produção.

Com a discussão sobre a epistemologia feminista pretendíamos delinear como a ciência de maneira interessada constrói seus objetos e como essa construção é um uso de poder, dando ênfase à abordagem inovadora das teóricas feministas que colocam seus campos de pesquisa como "campos científicos abertos e pouco ortodoxos, marcados pelo debate e pela diversidade analítica." (LOURO, 1995, p. 157). Campos onde a capacidade de criação de novas abordagens de análise parece possível, desde que se reconheça a necessidade de posicionar-se, sendo o "posicionar-se a prática chave, base do conhecimento organizado em 
torno das imagens da visão, é como se organiza boa parte do discurso científico e filosófico ocidental: posicionar-se implica em responsabilidade por nossas práticas capacitadoras" (HARAWAY, 1995, p. 27).

Assim, os estudos de mulheres colocam-se como aqueles que consideram a ciência como interpretação, como tradução, e relacionam-se a uma visão crítica e de posicionamento num espaço social não homogêneo. Visão que pretendemos apontar contra os argumentos de Freyre, como forma de desconstruir a notoriedade de suas contribuições no que tange às mulheres, objetivo deste trabalho, mas que pode ser estendida a outras perspectivas trabalhadas pelo autor pernambucano.

Muitos são ainda os temas passíveis de serem debatidos sobre a epistemologia feminista, como, por exemplo, a muito interessante discussão do sistema sexo/gênero, parte da construção dessa epistemologia feminista, mas que ultrapassa o interesse do trabalho que construímos aqui, estando ele vinculado a uma instrumentalização da construção dos discursos científicos, mais especificamente o elaborado por Freyre.

\section{Gilberto Freyre: análise de argumentos e misoginia}

Para falar das mulheres, Freyre assume como relatos de verdade as falas de homens brancos e estrangeiros, em sua maioria padres e médicos. Do ponto de vista de homens que detinham o poder, que controlavam de alguma forma a moralidade permissiva aos homens e restritiva às mulheres, é que é construída a narrativa freyriana da formação da sociedade brasileira. Essa escolha já demonstra a parcialidade da descrição que será elaborada, sobretudo porque as referências são tomadas como relatos fiéis da época, não sendo portanto alvos de crítica do autor, homem que nas primeiras décadas do século $\mathrm{XX}$, demonstra conhecer a lutas e a presença das feministas ${ }^{2}$ e também de mulheres que se dispuseram a questionar uma ordem que impõe padrões que ultrapassam aptidões naturais e se inscrevem num processo deliberado de exclusão de mulheres das instâncias de poder - como a ciência e a política - mas que não se convence da bandeira das feministas e elabora uma narrativa agressiva às mulheres.

A nossa análise não está estruturada na ordem de apresentação dos argumentos do autor até porque sua narrativa é fluida, havendo referências dos mesmos assuntos em diversos locais. Construiremos então uma sequiência que nos parece mais interessante para atingir os objetivos delineados no início do trabalho: dar a amplitude da misoginia no tratamento das 
mulheres nas obras de Freyre e apresentar reservas a seu uso como referência bibliográfica para trabalhos futuros que tenham como foco a presença das mulheres na história nacional.

Na obra de Freyre, apesar de inserções que analisam a influência da organização social e econômica no comportamento dos indivíduos, muitas das relações de subordinação e desigualdade entre indivíduos são tomadas como naturais; vinculadas a uma natureza ou de homem, ou de mulher, ou de branca(o), ou de negra(o), defendendo ele que a inobservância de condições e imposições biológicas relativas aos sexos só pode ser fruto do "fanatismo feminista" ou de "certa mística comunista-marxista". Em síntese, o autor de Casa Grande \& Senzala e Sobrados \& Mucambos acredita na essência de homens e mulheres, de brancos e negros que ultrapassa determinantes sociais, essência essa que durante sua narrativa é usada para hierarquizar brancos sobre negros e homens sobre mulheres. O que, como apontamos anteriormente, é combatido pelas teóricas das mulheres, pois há o entendimento da existência de vinculação dos indivíduos ao momento histórico e aos processos em que estão inseridos que ultrapassa essas determinações biológicas a que se apega Freyre. Na sociologia, mais recentemente, há também a ênfase no processo de socialização como formador do indivíduo, e tal concepção não se faz em uma mão única para muitos autores, há uma dupla influência: normas e controle social formam os indivíduos tal como os indivíduos atuam na formação, manutenção e inovação das normas.

$\mathrm{Na}$ busca dessa natureza aglutinadora, Freyre define a mulher como um elemento conservador e integrador, sentimental, com tendência à dissolução e ligada ao trabalho estável, sólido, contínuo; sendo essas características determinadas antes pelas possibilidades de ser mãe, pelas condições biológicas para fazê-lo, do que pelas especificidades históricas e materiais do momento em que a mulher está vivendo, como defendem Haraway, Dias e Swain. Na lógica freyriana o homem é definido pela natureza contrária: é a parcela móvel, militante e renovadora da sociedade patriarcal, com tendência à cristalização e ao trabalho violento e esporádico.

As mulheres, por sua tendência à subordinação e à dissolução, são aproximadas aos negros. Freyre defende que, na linguagem, ambos tendem a usar o tom de súplica enquanto os homens brancos expressam uma comunicação de mando, estando os dois - mulheres e negros - abaixo deles.

No Brasil, essas duas tendências individualistas, de raça e de sexo, teriam se unido no homem patriarcal, criador ou organizador dos valores mais característicos da nossa diferenciação social ou nacional. Esse criador foi 
principalmente o colonizador branco ou apenas manchado de sangue ameríndio ou africano (FREYRE, 2003, p. 218-9).

Dessa forma, a raça e o sexo são elementos centrais na obra de Gilberto Freyre para considerar os grandes e os pequenos atores nos esforços da colonização portuguesa. Assim, apesar da figura fundamental da mulher como ventre gerador e dos escravos no domínio da técnica agrícola de produção do café e do açúcar, para Freyre, o grande balizador da nação brasileira é o homem branco português, ou apenas o mestiço "manchado".

Tomando como referência a natureza conservadora da mulher e a renovadora do homem, Freyre defende ainda que é "o homem, o elemento de imaginação mais criadora e de contatos mais diversos e, portanto, mais inventor, mais diferenciador, mais perturbador da rotina. A mulher, o elemento mais realista e integrador" (FREYRE, 2003, p. 217). Partindo dessa afirmação pode-se dizer que a mulher dentro da sociedade patriarcal descrita por Freyre é o principal elemento de manutenção. Ainda que não se beneficie por essa ordem, fato a que o próprio Freyre se refere ao falar da fragilização da saúde das mulheres brancas e na sifilização das mulheres negras e índigenas na dominação pelos homens, elas tendem a aceitar e a promover a defesa da ordem instituída. É a imobilidade, mas, sobretudo, o conservadorismo que caracteriza a mulher. Para exemplificar seu argumento, Freyre cita o uso preferencial da liteira ao cavalo pela mulher. Fala ainda que toda a moda que exigia das mulheres brancas enormes sacrifícios, o uso do espartilho, dos longos vestidos e dos enormes penteados, foram modismos instituídos pelos bacharéis que, indo estudar na Europa, traziam, por serem homens, essa vontade de mudar e fazer algo novo, reafirmando-se, cristalizando-se em patriarcas viris, subordinando suas mulheres e enfraquecendo ainda mais a saúde delas que, por sua tendência natural à dissolução, à aceitação das imposições sociais ao invés do fortalecimento da própria figura, subjugavam-se às novas modas e formas de comportamento vindas da França e da Inglaterra.

Esquece-se assim das inúmeras mulheres que eram as chefes das casas, que representavam importante parcela das mulheres brancas e livres do período da colônia e do império. Essas mesmas mulheres são retratadas por Maria Odila Dias em trabalho que delinearemos a seguir.

Com relação a essa referência à cristalização masculina em contraposição à dissolução feminina, Freyre coloca que a mulher branca é impelida a não formar sua subjetividade, o que não é visto como ruim ${ }^{3}$. Ao contrário, Freyre defende a necessidade de maior objetividade entre as artes no Brasil, só possível com a inserção das mulheres, objetividade que não existe 
por serem as artes majoritariamente feitas por homens. No entanto, ao mesmo tempo em que pede uma ampliação da objetividade nas artes só possível, aparentemente, pela ação das mulheres, Freyre afirma que elas, com exceção de alguns nomes como o de Nísia Floresta, expressam-se de maneira insignificante, "reduzidas a formas graciosas. Graciosas e quase inócuas" (FREYRE, 2003, p.228).

Dessa discussão sobre a formação da subjetividade feminina Freyre parece oferecer uma saída que reforça a dissolução da identidade da mulher, que tende a manter sua subordinação à ordem patriarcal, ordem que a deforma e a deixa inerte ao poder do homem, seu pai ou marido. A proposta não é da ampliação da ação da mulher, mas da adequação da natureza dissoluta à ordem patriarcal. Nesse mesmo sentido uma questão precisa ser levantada: Freyre ao mesmo tempo em que atribui a péssima expressão graciosa e insignificante das mulheres à estrutura patriarcal da sociedade, em que o que é estimulado é exatamente a graça e a beleza femininas que reforçam a figura do homem, parece atribuir a não-participação das brasileiras nas artes como algo deliberado, uma escolha, mais que uma imposição da ordem patriarcal - o que é incoerente. Há então duas medidas que funcionam ao mesmo tempo e sobre o mesmo assunto de maneiras antagônicas para se analisar a inserção das mulheres: a vontade, possibilidade de escolher autonomamente a não-participação, e a vedação, imposta pelo sistema social.

A natureza conservadora, integradora e mais estável da mulher é também usada para analisar as indígenas, as primeiras produtoras, junto com os homens portugueses, da nação brasileira. Ao contrário dos homens, as mulheres das tribos brasileiras, segundo Freyre, deram as maiores contribuições à estabilização dos primórdios do que viria a ser o Brasil, aproveitando-se mais o que Freyre chama de parte feminina da cultura:

já dissemos, às primeiras páginas deste capítulo, que sob o ponto de vista da organização agrária em que se estabilizou a colonização portuguesa do Brasil, maior foi a utilidade social e econômica da mulher que a do homem indígena. (...)Melhor ajustamento se verificou da parte da mulher; o que se compreende, dada a sua superioridade técnica entre os povos primitivos; e dada a sua tendência maior para a estabilidade entre os povos nômades (FREYRE, 2005, p. 185).

Sobre as negras, no que se refere à estabilidade e conservadorismo, não há uma referência tão clara como a apresentada sobre as mulheres brancas e indígenas. No entanto, diante do argumento que se destina a uma natureza da mulher em geral e levando em consideração que Gilberto Freyre marca o comportamento das negras dentro de um quadro de passividade às normas do patriarcado brasileiro, não é exagerado tomar como descrição do 
comportamento delas um imobilismo e conservadorismo, uma aceitação de sua condição de cativas e de objeto sexual dos homens brancos, dos meninos e dos senhores.

Dentro ainda dos pontos de definição das mulheres brasileiras construídos por Freyre, falemos da rígida divisão sexual do trabalho, marco de referência para a separação do comportamento de homens e mulheres ${ }^{4}$. É a maior domesticidade ou publicidade dos trabalhos efetuados por um sexo ou por outro que vai determinar sua feminização, tendo "o homem a atividade violenta e esporádica; a mulher, a estável, sólida, contínua. Funda-se esse antagonismo na organização física da mulher, que a habilita antes à resistência que ao movimento. Antes à agricultura e à indústria que à caça e à guerra.” (FREYRE, 2005, p. 186). Sendo todas as atividades ligadas ao cuidado da casa e à domesticidade - ser as esposas ou concubinas, as mães de família, cozinheiras e amas de leite - as mais agradáveis ao sexo da mulher.

Concordando com esses papéis fortemente separados é que nascem as mulhereshomens e os homens-mulheres da obra de Freyre. Assim, as senhoras de engenho que assumiram os negócios dos maridos nas fazendas são como mulheres-homens, por serem capazes de dirigir as fazendas tal qual o faziam os homens que as antecederam. Da falta das mostras de masculinidade, de virilidade, ou ainda pela simples prática de alguma atividade doméstica é que muitos padres e indígenas são tratados na obra freyriana por efeminados.

Assim, o trabalho da couvade - o ato de lavar as redes sujas - desempenhado por homens em algumas tribos indígenas no Brasil os efeminaria. No entanto, mais uma vez aparecem duas medidas opostas para julgar comportamentos extremamente semelhantes, como vimos na participação das mulheres nas artes. Entre as mulheres indígenas seu trabalho ultrapassava as atividades restritas a casa, elas eram responsáveis pelo desenvolvimento da agricultura, mas isso não implica sua masculinização. Talvez porque aí não seriam mais tão atraentes ao colonizador português e nem capazes de participarem na formação de sociedade sensual como a brasileira. Quem ocuparia, no trabalho de Freyre, o espaço destinado às indígenas ávidas por homens brancos, dispostas a auxiliar na empresa da colonização como ventres geradores?

Entre os brancos a rigidez da separação entre o trabalho doméstico e o público gerava uma constante necessidade de reafirmação da masculinidade entre os homens e de uma forte observância das regras sociais entre as mulheres. A eles então eram necessárias mostras constantes de virilidade que se estendiam desde o menino de engenho até aos homens mais 
velhos. A elas o marcante recato e o abafamento de desejos sexuais que extrapolassem o aumento da prole.

Dessa necessidade de reafirmação da identidade de homem, das condições climáticas, da escravidão e das múltiplas influências das raças formadoras da nação brasileira é que nasce o erotismo exacerbado, outro ponto que na ótica freyriana caracteriza o Brasil e baliza as relações entre dominadores e dominados no território nacional - e que é interessante para o nosso trabalho na medida em que cristaliza formas de comportamento sexual de homens e mulheres e que amplia a justificação ou a responsabilização das mulheres na dominação que sofrem. Erotismo que se exprime pelo grande número de concubinatos; pelos inúmeros casos de adultérios, inclusive de mulheres brancas com padres e médicos, fiéis depositários da moral colonial e imperial; pelo desejo do senhor de engenho e do viajante pela mulatinha ainda jovem - com doze ou treze anos de idade; pelas indígenas que iam se esfregar nas pernas do colonizador, que "saltava em terra escorregando em mulher nua", "atolando o pé em carne" (FREYRE, 2005, p. 161). Mas que não se restringia à prática sexual e era percebido em todas as ocasiões, em procissões e em festas religiosas, e mesmo entre as freiras ${ }^{5}$.

A partir do poder do patriarca e da sua lassidão enquanto homem viril, desenvolve-se no Brasil uma dupla moral sexual. Uma mais frouxa, aplicada aos homens e que Freyre pretende justificar: primeiro pela necessidade de povoar a Colônia - "os interesses de procriação abafaram não só os preceitos morais como os escrúpulos católicos de ortodoxia" (FREYRE, 2005, p. 325); depois pela ação do clima tropical e das condições bioquímicas nos homens portugueses, ampliando o seu desejo sexual. Freyre não abandona completamente a influência da organização social e de poder para essa dupla moral sexual, mas não deixa de atribuir às mulheres negras e indígenas, que se submetiam aos desejos dos homens brancos, uma moralidade inferior, assim "onde (a corrupção do colonizador) não se realiza através da africana, realiza-se através da índia" (FREYRE, 2005, p. 398). A outra moral destinada às mulheres brancas pregava o recolhimento e o estreito relacionamento com seus maridos, sua devoção à família - aos muitos filhos e ao marido - à Igreja e a aproximação à figura da Virgem Maria.

Como marca dessa frouxa moral sexual entre as raças diferentes, desenvolvem-se as relações entre dominadores e dominados com base no sadismo dos primeiros e do masoquismo dos últimos. Assim à violação de negras e indígenas pelos senhores Freyre coloca: 
uma espécie de sadismo do branco e de masoquismo da índia ou da negra terá predominado nas relações sexuais como nas sociais do europeu com as mulheres das raças submetidas ao seu domínio. O furor femeeiro do português se terá exercido sobre vítimas nem sempre confraternizantes no gozo; ainda que se saiba de casos de pura confraternização do sadismo do conquistador branco com o masoquismo da mulher indígena ou negra (FREYRE, 2005, p. 113).

Apesar de considerar a não completa aceitação por parte das mulheres dominadas da presença e da imposição sexual dos senhores, Freyre em nenhum momento, mesmo nas linhas em que ele apresenta certa contrariedade ao apontar uma organização sexual que favorecia a vontade dos homens brancos - ou mesmo dos meninos brancos - , deixa de apontar alguma concordância da cativa aos avanços do europeu. É interessante questionar se havia de fato toda essa aceitação, primeiro porque as referências de Freyre são, como já dissemos, muito parciais e, segundo, como atribuir a meninas negras e indígenas de doze ou treze anos e mesmo a escravas mais velhas - de acordo com dados apresentados por Freyre - acostumadas desde sempre a obedecer a, de um momento a outro, estabelecerem-se como grandes dominadoras, donas de um desejo sexual insaciável.

O sadismo disperso nas relações sociais brasileiras é ensinado desde cedo ao menino de engenho que vai praticá-lo nas suas brincadeiras, em que a intenção é a de destruir e de colocar-se como superior - beliscar, quebrar peões, derrubar a pipa dos outros - e submeter negrinhos e negrinhas a seus desejos. Assim se expressa, em Casa-grande \& Senzala, o comportamento sádico dos meninos:

Em outros vícios escorregava a meninice dos filhos do senhor de engenho; nos quais, um tanto por efeito do clima e muito em conseqüência das condições de vida criadas pelo sistema escravocrata, antecipou-se sempre a atividade sexual, através de práticas sadistas e bestiais. As primeiras vítimas eram os moleques e animais domésticos; mais tarde é que vinha o grande atoleiro de carne: a negra ou a mulata. Nele é que se perdeu, como em areia gulosa, muita adolescência insaciável(FREYRE, 2005, p. 455),

sendo as negras as grandes responsáveis pela perdição dos meninos de engenho, não sua formação para ser deflorador e garanhão.

Todo esse erotismo e o sadismo influenciados pelo escravismo: "nessa instituição social - a escravidão - é que encontramos na verdade o grande excitante da sensualidade entre os brasileiros. Talvez o maior, em Portugal, abaixo da necessidade de gente para a tarefa da colonização" (FREYRE, 2005, p. 332), assim, o erotismo e o sadismo que submetem e maltratam mulheres indígenas, brancas e negras e favorecem unicamente o homem branco português tem a sua explicação elaborada por Gilberto Freyre a partir da defesa de que seriam 
consequiências normais do regime de escravidão e de que seria necessidade que ultrapassa uma escolha e o desejo de subjugar, de marcar a posição de poder ocupada pelos homens brancos que, mais que garantir o sucesso da empresa colonizadora por meio da reprodução com negras e indígenas ${ }^{6}$, necessitavam dessas mulheres para reafirmar constantemente sua superioridade de dominador. É preciso entender esse erotismo e o sadismo só desempenhados prazerosamente pelos homens portugueses ${ }^{7}$, apesar de toda a atribuição da voluptuosidade a negras e indígenas, não como uma consequiência automática da escravidão, mas como uma escolha, escolha feita por quem tinha condições de escolher, que não estava vinculado às amarras da violência contra si no momento de decidir.

Como finalização e para marcar ainda mais o tratamento de Freyre às mulheres daremos ênfase a pontos de descrição de negras, indígenas e brancas.

\section{Mulheres negras e indígenas}

Na descrição que Freyre faz das mulheres negras em ambos os livros destacamos como pontos importantes para a análise: a sensualidade exacerbada e a superexcitação das negras que, assim como entre os indígenas, se contrapõe a uma retração sexual do homem; a sua condição de escravas como fonte de corrupção da sua relação com a família branca.

Como forma de justificar ou humanizar os abusos contra a mulher e o homem negros e indígenas em diversas situações e as posteriores construções que degradaram sua imagem como criaturas desprovidas de qualquer tipo de decência moral, Freyre elabora uma separação entre escrava e negra. Essa divisão permite ao autor atribuir todas as características não positivas vinculadas à negra à figura da escrava; submetida aos desejos do homem branco, quem seria o verdadeiro corruptor, mas que, devemos insistir, sai com as mãos limpas na narrativa de Freyre, compensado pelo "enorme" esforço da colonização. Em muitos momentos, a escrava passa de vítima a algoz no sistema de economia canavieira, do patriarca, sendo a ela vinculado o papel de corruptora da família patriarcal, seja na língua ou na forma de se comportar. Ela passa de prostituída e violada àquela que é voluntariamente prostituta pela atração pelo homem branco.

Corrupção da negra que facilitou "a depravação com a sua docilidade de escrava; abrindo as pernas ao primeiro desejo do sinhô-moço. Desejo, não: ordem" (FREYRE, 2005, p. 456). "Ninguém nega que a negra ou a mulata tenha contribuído para a precoce depravação do menino branco da classe senhoril; mas não por si, nem como expressão de sua raça ou do seu meio-sangue: como parte de um sistema de economia e de família: o patriarcal brasileiro" 
(FREYRE, 2005, p. 457). Mesmo apresentando a distinção entre escrava e negra, Freyre em vários momentos abandona essa fraca divisão construída por ele e iguala escravas e negras a negras - eram as escravas e os escravos e não as negras e os negros que produziam a depravação da sociedade colonial brasileira, negras e negros eram elementos civilizadores, no entanto, pela precariedade dessa divisão, o próprio Freyre confunde os dois elementos sendo eles os corruptores da nação por sua raça e não por sua condição social de escravizados. É bastante peculiar essa referência quando o autor trata da preferência portuguesa pelas mulheres negras como escolha pelas mulheres fáceis, mais acessíveis que as brancas - "do menino sempre rodeado de negra ou mulata fácil” ( FREYRE, 2005, p. 368) - e fáceis não somente porque eram cativas mas também porque escolhiam sê-lo na ótica freyriana.

Muito do que foi dito com relação às mulheres negras vale para as mulheres indígenas. Elas são vistas por Freyre, a partir da perspectiva do homem português como desejosas de sexo que "por qualquer buginganga ou caco de espelho estavam se entregando, de pernas abertas aos 'caraíbas' gulosos de mulher”(FREYRE, 2005, p. 71). Sendo a sua moral sexual tão frouxa quanto a do homem português, tendo se encontrado no Brasil duas raças de comportamento sexual semelhante, desejosas de todos os prazeres possíveis.

Com essa argumentação, Freyre reforça o mito da mulher branca e inatingível, referência da mulher nacional, recatada, em contraposição a mulheres indígenas e negras que se destacam por sua depravação e desejo sexual desmesurado, as mães geradoras da nação brasileira, sensual e dedicada aos prazeres da carne. Essa imagem nacional é ainda amplamente aceita e é um dos incentivos ao turismo no país, a busca por essa perdição sexual entre belas e exóticas mulatas e negras brasileiras.

\section{Mulheres brancas}

Na obra de Freyre as mulheres brancas assumem o espaço de mulheres sobre as quais a moral se impõe de forma diferenciada que em relação a negras e indígenas. A elas está vinculada a figura da Virgem Maria e da pureza na descrição de Freyre. Essas mulheres também são analisadas a partir da ótica da dominação exercida por seus pais e maridos sobre elas e da sexualidade congelada que se realiza parcialmente nos carinhos das amas negras, alvos mais freqüentes da raiva das senhoras.

Essas mulheres brancas especializavam-se em belo sexo, lânguidas quando moças e gordas e flácidas quando matronas, ao contrário das negras. Casavam-se cedo: "Foi geral o costume no Brasil de as mulheres casarem cedo. Aos doze, treze, quatorze anos" (FREYRE, 
2005, p. 429) pois no Brasil a velhice para as mulheres brancas chegava aos vinte anos. Com essa idade já deviam ser mães de vários filhos, vivos e mortos. Na descrição de Freyre sua saúde era extremamente fraca, muito influenciada pelo sistema patriarcal que as queria muito diferentes dos homens, como já colocamos anteriormente.

A ilibada moral das mulheres portuguesas é amplamente defendida por Freyre, por exemplo, contrapondo-se a um viajante desconhecido que coloca as mulheres brancas brasileiras como muito enclausuradas, mas muito libertinas, mais do que em outros lugares. Contrapõe-se também a Manuel Bomfim quando este descreve a prática das iaiás de deitaremse com negros para contrariar os pais. Para Freyre, as senhoras brancas se contrapõem às negras, eram castas, recolhidas, sisudas e modestas. É dentro da correspondência a essa moral tão restritiva a qualquer tentativa de liberação das mulheres brancas que Freyre se coloca como aliado e defende a prática das mulheres da época.

A sua defesa dessa moralidade chega a considerar que o papel desempenhado por padres e médicos ao conversar com as senhoras servia para reduzir suas angústias, que esse não era, como defende Mary Del Priore (1993), um expediente patriarcal para controlar as atividades das mulheres, estabelecendo uma moral cristã e mais tarde um cuidado da saúde que mais serviam a manter as mulheres subservientes aos maridos e pais que a verdadeiramente promover sua desintoxicação.

O sadismo de que fala Freyre para os homens brancos encontra correspondência entre as mulheres quando se trata do ciúme delas pelas negras bonitas, de quem se suspeitasse ter atraído o desejo do marido. Muitos então são os casos de tortura e de assassinato das mulheres negras por sinhás por ciúmes, ciúmes que se fundam mais uma vez para reforçar a posição do marido de grande dominador, por quem se toma as mais impactantes decisões contra a natureza sentimental.

Acreditamos que todos esses elementos deixam claro que a narrativa freyriana de construção da imagem da brasileira privilegia elementos profundamente misóginos, que concordam com a participação marginal das mulheres no poder. Como referência bibliográfica para estudos das mulheres é inadequada porque defende uma natureza única e definidora de mulheres, essencializando discussões e reduzindo os impactos da dominação dos homens sobre as mulheres brasileiras.

Partimos agora para a análise de obras das teóricas das mulheres, destacando a necessidade do uso crítico e atento da obra freyriana como base de dados para qualquer 
trabalho que pretenda fugir aos vícios de uma identidade da mulher brasileira, que saiba da multiplicidade identitária que os estudos devem ser capazes de englobar.

\section{A herança freyriana em trabalhos recentes de história das mulheres no Brasil}

Muitas são as obras que pretendem dar relevo à figura da mulher brasileira na história nacional, mas seja por falta de fontes bibliográficas, seja por uma escolha deliberada ou resistência a empreender as críticas que prevê a história das mulheres, a obra de Freyre é referência se não direta, indireta em marcas pontuais ao longo da narrativa de muitos trabalhos a que tivemos acesso.

Não foi feito um recorte específico além do temporal. Em consulta à base de livros da Biblioteca da Universidade de Brasília escolhemos as obras que enfocassem as mulheres no período entre o Brasil Colônia e o século XIX, no Império. A idéia inicial era de achar argumentos que se contrapusessem à estrutura da argumentação de Freyre, mas diante das tentativas sem sucesso achamos melhor então chamar atenção para a necessidade das teóricas brasileiras elaborarem uma crítica mais sistemática de obras que apresentam o grau de misoginia apresentado por Freyre nas páginas de seus livros.

Entre as obras escolhidas para esse trabalho não há nenhuma que não traga como referência um dos livros escolhidos, Casa Grande \& Senzala ou Sobrados \& Mucambos. Os livros e artigos que escolhemos são: Ao Sul do Corpo: condição feminina, maternidades e mentalidades no Brasil Colônia de Mary del Priore; Quotidiano e poder em São Paulo no século XIX de Maria Odila da Silva Dias; Aprendendo a ser mulata: um estudo sobre a identidade da mulata profissional e Mulher e escrava: uma introdução histórica ao estudo da mulher negra no Brasil artigo e livro, respectivamente, de Sônia Maria Giacomini; Virtude e Pecado em São Paulo Colonial de Eliana Maria Goldschimdt e O Autoritarismo e a Mulher de Maria Inácia D’Ávila Neto. Repetimos que nas obras lidas nenhuma, com exceção do livro de Maria Odila Dias, vincula uma crítica mais explícita da narração elaborada por Freyre, sua estrutura argumentativa ou suas referências.

Assim as figuras da mãe, da mulata sensual, da sexualidade desbragada de mulheres negras indígenas contraposta ao completo esquecimento do desejo e da prática sexuais da mulher branca, e outras persistem nas páginas dos trabalhos de brasileiras no que se refere ao cotidiano das mulheres no Brasil Colônia e Império. Assim, essas páginas são uma construção reiterada das figuras tão amplamente questionadas pela desconstrução de uma identidade fixa 
da mulher, como é a proposta apresentada por teóricas da epistemologia feminista ${ }^{8}$, como problematizamos no início do trabalho.

O único trabalho das obras consultadas que foge ao formato de aceitação da construção das mulheres até então existentes é o de Maria Odila Dias, em Quotidiano e Poder em São Paulo no século XIX, em que a autora busca pôr em evidência a vida das quitandeiras e padeiras, questionando severamente as fontes consultadas, inclusive Freyre, alegando um esquecimento sistemático das mulheres nas obras dos cientistas sociais brasileiros em que elas "ficaram ignoradas, à margem das obras de historiadores, mesmo do quotidiano, que mal deram por sua existência.” (DIAS, 1995, p. 29), como se deveras a empresa colonizadora e de formação da nação brasileira fosse esforço apenas do homem português, sendo desempenhado sem a presença de mulheres. Dias apresenta dados que se referem à liderança de mulheres em diversas casas urbanas de São Paulo. A autora confronta ainda os mitos com relação à mulher branca - a mulher branca inatingível, modelo formado para congelar o comportamento feminino e marginalizar mulheres negras, indígenas e mesmo brancas pobres - deixando claro que essas construções serviam para aumentar a marginalidade das mulheres que não se enquadravam nos padrões restritos de mulheres brancas e ricas.

Maria Inácia Neto, em $O$ autoritarismo e a mulher, procura determinar quais são as raízes do autoritarismo contra as mulheres no meio urbano. A autora faz então uma reconstrução da trajetória do patriarcalismo no Brasil, até o período colonial. Para tratar dessa gênese o trabalho de Gilberto Freyre coloca-se como referência. À continuação do trabalho, a autora, assim como Freyre, defende uma natureza feminina conservadora fortalecida pela restrição do espaço da mulher estar vinculado ao doméstico, sem possibilidades de viajar e conhecer novas idéias, estando submetida aos desejos do pai e do marido. Como conclusões do trabalho, Neto apresenta a necessidade da observação das especificidades das mulheres, considerando suas trajetórias a partir da raça e classe social, e defende que o patriarcalismo, tal qual existia no Brasil colônia ainda vincula a mulher ao culto da virgindade e o homem ao da virilidade. Nenhum questionamento de como essa ordem patriarcal é entendida por Freyre ou do congelamento do comportamento feminino na descrição do autor é colocada por Neto.

Sônia Maria Giacomini trata das mulheres negras nos textos que escolhemos como referências. No livro, Mulher e escrava: uma introdução ao estudo da mulher negra no Brasil, a autora pretende reelaborar a história da escravidão brasileira e compreender as raízes históricas da situação da mulheres e trabalhadoras negras no Brasil. Apesar dos objetivos de releitura da historiografia no que diz respeito à trajetória das mulheres negras, o livro não traz 
muitas respostas inovadoras. São lançadas inúmeras críticas à falta de bibliografia, e de referências documentais à presença das mulheres negras e escravas no Brasil, fato que imobiliza a argumentação de Giacomini. Dentro dessa falta de material para a pesquisa a autora propõe algumas perguntas que não são respondidas ou ao menos problematizadas, só são lançadas, fugindo a um maior contraditório, fugindo do que se poderia prever a partir dos objetivos propostos no início do trabalho dela. A falta dos relatos das mulheres negras na historiografia oficial parece produzir um impeditivo para qualquer construção de uma história das escravas, parece que o silêncio provocado pela ordem de poder de outrora cala qualquer possibilidade ou esforço analítico que possa surgir.

Muitos dados interessantes e que poderiam ser contrapostos à visão de Freyre são apresentados por Giacomini, dentre eles é interessante citar: o baixo interesse por parte dos senhores na reprodução das escravas negras devido ao aumento dos custos de manutenção do gentio, argumento que bate de frente com a necessidade de povoamento descrita por Freyre e que é a base de justificação do erotismo e da moral sexual mais frouxa. Argumento semelhante ao de Giacomini é elaborado por Boris Fausto em sua História do Brasil. O autor defende que o meio preferido de substituir os escravos que morriam jovens pelo péssimo tratamento que recebiam nas senzalas brasileiras era a importação de novos escravos:

com raras exceções, não houve tentativas de se ampliar o crescimento da população escrava já instalada no Brasil. A taxa de fertilidade das mulheres negras era baixa. Além disso, criar uma criança por doze ou catorze anos era um investimento de risco, tendo-se em conta as altas taxas de mortalidade, decorrentes das próprias condições de existência (FAUSTO, 1998, p. 54).

Como resistência das mulheres negras, Giacomini faz referência ao grande número de infanticídios e abortos praticados por elas, como forma de defender essas crianças do sistema escravocrata, ponto nem abordado por Freyre, dada a construção idílica feita por ele da condição da mulher escrava.

Outro ponto trazido por Giacomini é a grande dificuldade dos escravos em formarem famílias. Por serem tratados como "coisas" não era previsto que formassem alguma subjetividade, assim as famílias de escravos eram praticamente inexistentes no período. Freyre também não fala dos maridos negros de negras que cometeram assassinatos por ciúmes de suas esposas, diante da compulsoriedade da prática sexual com os senhores, fato a que Giacomini faz referência. Em Freyre, a figura do homem negro como parte de relação sexual só tem espaço ao se falar da ação violenta deles contra as mulheres indígenas, as mesmas que se entregavam, sem resistência, ao colonizador branco. 
A argumentação de Giacomini anima por trazer novas referências à discussão da formação nacional, mas perde o fôlego quando a autora passa a tratar das mães-negras e das mulheres negras como objeto sexual, sendo a mesma lógica desenvolvida no artigo Aprendendo a ser mulata: um estudo sobre a identidade da mulata profissional. Ela retoma o argumento freyriano da participação fundamental da negra como base de desenvolvimento e crescimento dos filhos da casa grande. E ao tratar da sensualidade da negra e da mulata, apesar de se contrapor fortemente a Freyre, não apresenta uma crítica mais enfática à institucionalização dessa negritude sensual e da moral sexual frouxa atribuída às mulheres negras, preconceito que ainda hoje é vigente e que se reforça por constituir uma das bases da mobilidade social das mulheres negras brasileiras. $\mathrm{O}$ ataque que é feito aos argumentos de Freyre por Giacomini, é defender que o que ele desenha em seus textos a figura da mulher negra como a "embaixadora da senzala na casa grande e vice-versa", crítica que ocupa duas linhas nas noventa páginas em que o livro se estrutura. Não estamos defendo uma mudança na linha de argumentação da autora, mas se a presença de Freyre é necessária que se faça uma crítica mais consistente, englobando os diversos argumentos que possam explorar os preconceitos construídos contra as mulheres a partir de sua argumentação.

Em Ao Sul do Corpo, Mary del Priore destaca o controle do corpo da mulher branca por padres e por médicos, como forma de subjugá-las. Ao contrário de Freyre, não estabelece que as figuras de padres e médicos sejam formas de aliviar as tensões cotidianas da vida das mulheres, ao contrário atribui essa presença ao constante controle de comportamento das mulheres brancas, que, de fato, interessavam à coroa portuguesa no momento do aumento da população no Brasil, ao contrário do argumento freyriano, de um crescimento indiscriminado de mestiços na população nacional. Del Priore, no entanto, destaca a importante contribuição de Freyre na determinação das heranças de negras, indígenas e brancas na colonização portuguesa no Brasil. É intrigante que o reconhecimento do trabalho de Freyre se coloque no trabalho de Del Priore sem uma atenção maior às imagens construídas para as mulheres brasileiras já que a intenção da autora é exatamente explorar as fontes de controle das mulheres para sua realização como mães e nada mais. Fontes de controle (padres e médicos) que Freyre defende como os grandes auxiliadores das mulheres, aqueles que as auxiliavam a relaxar a mente, a conversar com elas como amigos, assim como as mucamas o faziam.

Diante do exposto sugerimos uma atenção mais ampla ao uso de autores que têm como foco a essencialização de papéis desempenhados por mulheres e homens, tal como o faz Gilberto Freyre. Entre as obras recentes escolhidas sobre as mulheres brasileiras, falta o 
esforço crítico a que se propõe a epistemologia feminista ou a história das mulheres. Uma disposição maior para o contraditório, para enfrentar nomes da academia brasileira, como o de Freyre, que constroem uma narrativa problemática porque presa a um modelo fixo de identidade. Na perspectiva de uma história das mulheres, faz-se essencial a construção de abordagens que critiquem um processo contínuo de construção de normatividades sobre o comportamento de mulheres e de naturalização do estabelecimento do poder masculino e que sejam capazes de enfatizar esses problemas em quaisquer abordagens, mesmo quando se trate de autor consagrado na academia brasileira.

\section{NOTAS}

${ }^{1}$ Tratamos o conceito de minoria a partir da participação das mulheres nas instâncias do poder, considerando sua participação efetiva como membros da elite decisória. Nesses espaços as mulheres são, ainda, minorias. Ainda que sejam a maioria na população nacional.

${ }^{2}$ Freyre cita Ruth Benedict, Nísia Floresta, faz um ataque às feministas e durante toda a narrativa não toma os argumentos delas como base de análise.

${ }^{3}$ É importante lembrar que essa subjetividade só é possível a homens e mulheres brancas, pois, em tempos de escravidão, negras, negros e indígenas não eram tidos como pessoas, mas como propriedade.

${ }^{4}$ Essa divisão não é amplamente explorada por Freyre no que diz respeito ao trabalho de negras e negros, talvez porque ambos devessem estar aptos a desempenhar os mesmos papéis na casa-grande e nos sobrados. Exceto se a beleza os fizesse cair nas graças dos senhores, tornando-se trabalhadores domésticos, o que parece, segundo a narrativa freyriana, uma espécie de ascensão social, pela qual sempre primou a colonização portuguesa.

5 As procissões e as festas a São Benedito, santo concedido pelos senhores e a Igreja aos escravos, eram "festivais não só de amor, mas de fecundidade. Danças desenfreadas ao redor da imagem do santo. Danças em que o viajante viu tomar parte o próprio vice-rei, homem já de idade, cercado de frades, fidalgos, negros. E de todas as marafonas da Bahia. Uma promiscuidade ainda hoje característica das nossas festas de igreja."(FREYRE, 2005, p. 329), espelhada em cultos orgiásticos africanos, África que se torna em muitos momentos a principal responsável pela frouxidão da moral sexual no Brasil, tema muito contraditório na obra de Freyre. A culinária é também impregnada de erotismo, nas cozinhas das negras e das freiras, mulheres intocáveis que seduziam muitos homens pelos doces: "suspiros de freira, toucinho-do-céu, barriga-de-freira, manjar do céu, papos-de-anjo. Eram os bolos e os doces porque suspiravam os freiráticos à portaria dos conventos. Não podendo entregar-se em carne a todos os seus adoradores, muitas freiras davam-se a eles nos bolos e caramelos. Estes adquiriram uma espécie de simbolismo sexual." (FREYRE, 2005, p. 330), assim as mulheres brancas conformadas a uma vida sexual austera, que se opunha à desbragada sexualidade de negras e indígenas, participavam da sexualidade sem limites que parecia, a partir do relato de Gilberto Freyre, dominar os espaços de convivência entre homens e mulheres.

${ }^{6}$ Durante a pesquisa os trabalhos de Sonia Maria Giacomini e a leitura de Boris Fausto se contrapuseram a essa argumentação de Freyre. A defesa elaborada por esses autores é de que não havia um estimulo à procriação de mulheres negras e muitas mães abortavam ou matavam seus filhos como forma de livrá-los da escravidão. Interessante também são as relações construídas por Maria Odila Dias em que a gravidez da negra passa a ser rentável devido a possibilidades de locação como amas-de-leite.

${ }^{7}$ Freyre faz referência ao sadismo das mulheres brancas contra as negras por ciúmes de seus maridos. Muitos são os relatos de surras, deformações no rosto e em partes do corpo como forma de mutilação da beleza das negras, como forma de evitar a traição e o concubinato dentro da casa grande e do sobrado, prática muito comum entre os homens na época.

${ }^{8}$ Como as autoras que tratamos no início do trabalho: Guacira Louro, Tânia Swain, Maria Odila Dias, Joan Scott, Louise Tilly, Rachel Soihet, Donna Haraway. 


\section{Referências Bibliográficas}

DEL PRIORE, Mary Ao Sul do Corpo: condição feminina, maternidades e mentalidades no Brasil Colônia. Rio de Janeiro: José Olympio; Brasília: EdUnB, 1993.

DIAS, Maria Odila Leite da Silva Quotidiano e poder em São Paulo no século XIX. São Paulo: Ed. Brasiliense, 1995.

Teoria e método dos estudos feministas: perspectiva histórica e hermenêutica do cotidiano in BRUSCHINI, Cristina e COSTA, Albertina de Oliveira (orgs.) Uma questão de gênero. Rio de Janeiro: Rosa dos Tempos, 1992, pp. 39-53

FAUSTO, Boris História do Brasil. São Paulo: Edusp, 1998

FREYRE, Gilberto Casa Grande \& Senzala: formação da família brasileira sob o regime de economia patriarcal. 50 a edição. São Paulo: Global, 2005.

Paulo: Global, 2003.

Sobrados \& Mucambos: decadência do patriarcado e desenvolvimento do urbano. São

GIACOMINI, Sônia Maria Aprendendo a ser mulata: um estudo sobre a identidade da mulata profissional in BRUSCHINI, Cristina e COSTA, Albertina de Oliveira (orgs.) Entre a virtude e o pecado. Rio de Janeiro: Rosa dos Tempos; São Paulo: Fundação Carlos Chagas, 1992, (pp.213-245).

Vozes, 1988. Mulher e escrava: uma introdução histórica ao estudo da nulher negra no Brasil. Petrópolis:

GOLDSCHMIDT, Eliana Maria Virtude e Pecado em São Paulo Colonial in BRUSCHINI, Cristina e COSTA, Albertina de Oliveira (orgs.) Entre a virtude e o pecado. Rio de Janeiro: Rosa dos Tempos; São Paulo: Fundação Carlos Chagas, 1992, (pp.15-36).

HARAWAY, Donna Saberes localizados: a questão da ciência para o feminismo e o privilégio da perspectiva parcial in Cadernos Pagu: Situando diferenças. Campinas: Unicamp/NEG, n. 5, pp. 7-41.

LOURO, Guacira Lopes Uma epistemologia feminista in Gênero, sexualidade e educação: uma perspectiva pósestruturalista. Petrópolis: Vozes, 1998, pp. 142-160

NETO, Maria Inácia D’Ávila. O Autoritarismo e a Mulher. Rio de Janeiro: Achiamé, 1980.

SCOTT, Joan W. Relendo a História do Feminismo in A Cidadã Paradoxal. Florianópolis: Ed. Mulheres, 2002, (pp. 23-48).

SOIHET, Rachel História das Mulheres in CARDOSO, Ciro Flamarion e VAINFAZ, Ronaldo Domínios da História: ensaios de teoria e metodologia. Rio de Janeiro: Campus, 1997, pp. 275-311.

SWAIN, Tânia Navarro Identidade, para que te quero? In GONÇALVES, Ana Teresa ; SOUZA, Armênia; SERPA, Élio e BITTENCOURT, Libertad Escritas da história: intelectuais e poder. Goiânia: Ed. UCG, 2004, pp. 35-52.

TILLY, Louise Gênero, História das Mulheres e História Social in Cadernos Pagu. Campinas: Unicamp/NEG, 1994, n. 3, (pp29-62). 